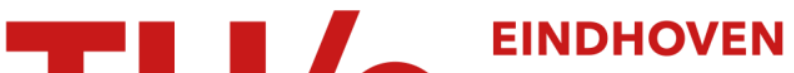

\section{High resolution optical frequency domain reflectometry for measurement of waveguide group refractive index}

\section{Citation for published version (APA):}

Zhao, D., Pustakhod, D., Williams, K. A., \& Leijtens, X. J. M. (2017). High resolution optical frequency domain reflectometry for measurement of waveguide group refractive index. In 2017 IEEE Photonics Conference (IPC), 1-5 October 2017, Orlando, Florida (pp. 537-538). Institute of Electrical and Electronics Engineers. https://doi.org/10.1109//PCon.2017.8116212

DOI:

10.1109/IPCon.2017.8116212

Document status and date:

Published: 20/11/2017

\section{Document Version:}

Accepted manuscript including changes made at the peer-review stage

\section{Please check the document version of this publication:}

- A submitted manuscript is the version of the article upon submission and before peer-review. There can be important differences between the submitted version and the official published version of record. People interested in the research are advised to contact the author for the final version of the publication, or visit the $\mathrm{DOI}$ to the publisher's website.

- The final author version and the galley proof are versions of the publication after peer review.

- The final published version features the final layout of the paper including the volume, issue and page numbers.

Link to publication

\section{General rights}

Copyright and moral rights for the publications made accessible in the public portal are retained by the authors and/or other copyright owners and it is a condition of accessing publications that users recognise and abide by the legal requirements associated with these rights.

- Users may download and print one copy of any publication from the public portal for the purpose of private study or research.

- You may not further distribute the material or use it for any profit-making activity or commercial gain

- You may freely distribute the URL identifying the publication in the public portal.

If the publication is distributed under the terms of Article 25fa of the Dutch Copyright Act, indicated by the "Taverne" license above, please follow below link for the End User Agreement:

www.tue.nl/taverne

Take down policy

If you believe that this document breaches copyright please contact us at:

openaccess@tue.nl

providing details and we will investigate your claim. 


\title{
High Resolution Optical Frequency Domain Reflectometry for Measurement of Waveguide Group Refractive Index
}

\author{
Dan Zhao ${ }^{1}$, Dzmitry Pustakhod ${ }^{1}$, Kevin Williams ${ }^{1}$ and Xaveer Leijtens ${ }^{1}$ \\ ${ }^{1}$ Eindhoven University of Technology, Dept. of Electrical Engineering, Den Dolech 2, 5612 AZ, Eindhoven, the Netherlands \\ d.zhao@tue.nl
}

\begin{abstract}
We present a high-resolution optical frequency domain reflectometry for characterization of group refractive index of waveguides in photonic integrated circuits. The method provides a relative accuracy of $10^{-4}$ for group refractive index measurements and of $10^{-3}$ for its dispersion.
\end{abstract}

\section{INTRODUCTION}

Optical parameters such as propagation loss, group and phase refractive indices can provide a measure for the quality and reproducibility of the technological process of photonic integrated circuits (PICs). The measurement of these parameters, including their wavelength dependence and the statistics of their variability, is critically important for understanding the behavior of PICs and for tracking fabrication errors[1]. It is possible to discover the variations in waveguide dimensions by characterization of group refractive index, but this requires a very accurate method. Many approaches have been proposed in literature[1,2]. On-chip interferometers have been used to experimentally extract the group refractive index with high accuracy, but such structures cannot be embedded alongside target devices[1]. Optical frequency domain reflectometry (OFDR) enables measurement of group refractive index within a compact single waveguide structure. However, the accuracy is limited by the temporal resolution of the method[2]. In our work, we propose and validate a high resolution OFDR method with deembedded group velocity dispersion to improve measurement accuracy for the group refractive index by an order of magnitude. The method also provides an estimation of the wavelength dependence of group refractive index with a relative accuracy of $10^{-3}$. To our knowledge, this data surpasses other OFDR-results published to date. Finally, we have experimentally confirmed the temporal resolution of the OFDR method and we have applied this method to characterize the group refractive indices of shallow- and deep-etched waveguides.

\section{OFDR METHOD AND ACCURACY}

The working principle of the OFDR method has been discussed in reference[3]. It is possible to determine the group refractive index of the straight waveguides in as-cleaved chips based on eq. (1)[4].

$$
n_{g}=c \frac{\tau_{b}-\tau_{f}}{L_{\text {chip }}}
$$

where $\mathrm{c}$ is the speed of light in vacuum, $\tau_{\mathrm{f}}$ and $\tau_{\mathrm{b}}$ are the time delays of front and back facet reflections and $L_{\mathrm{chip}}$ is the length of the integrated chip. The accuracy of the group refractive index is then determined by 1 . the chip length and 2. the measured time delay difference.

A. The relative error of the chip length
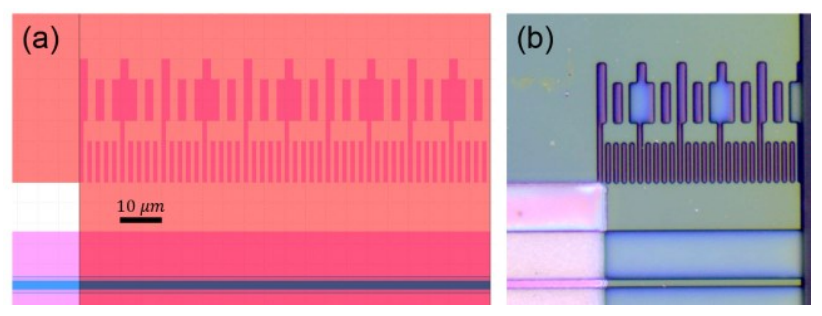

Fig. 1. (a) Mask and (b) microscope photograph of the on-chip micro-scale ruler.
The variation of the chip length, $\delta L_{\text {chip, }}$ may be determined from the cleaving process, which can be up to tens of micrometers. In this work, we have designed an on-chip micro-scale ruler at the four corners of the chip to measure the chip length after cleaving with measurement accuracy limited by microscope imaging to approximately $1 \mu \mathrm{m}$. Fig. 1(a) shows the mask layer definition of the ruler. Fig. 1(b) shows the microscope photograph of the fabricated ruler after cleaving. In our case, this results in a relative error of the chip length $\left(\delta L_{\text {chip }} / L_{\text {chip }}\right)$ of $2 \cdot 10^{-4}$, where $L_{\text {chip }}$ is $4600 \mu \mathrm{m}$.

\section{$B$. The relative error of the time delay difference}

The error of the time delay difference $\delta\left(\tau_{\mathrm{b}}-\tau_{\mathrm{f}}\right)$ in an ideal waveguide is inversely proportional to the frequency span $(1 / \Delta f)$ [4]. However, non-linear waveguide dispersion leads to a broadening of the reflection peaks which are observed in OFDR[5]. Therefore, the waveguide dispersion must be de-embedded to improve the temporal 
resolution. We provide a numerical algorithm to realize it: First, we sequentially apply the FFT to spectral windows. Each window is defined by the central wavelength $\lambda_{\mathrm{i}}$ and the width of the rectangular window $\Delta w$. This allows the extraction of the temporal traces at different wavelengths $\lambda_{\mathrm{i}}$. Second, the group refractive index at each $\lambda_{\mathrm{i}}$ is defined according to eq. (1). The time delay differences are retrieved from the first step. A narrow $\Delta w$ contributes to a good estimation of group refractive index at $\lambda_{\mathrm{i}}$ due to small dispersion, while at the expense of a poor temporal resolution. A $\Delta w$ of $20 \mathrm{~nm}$ gives a relative temporal resolution of $3 \cdot 10^{-3}$. Third, the effective refractive index $n_{\text {eff }}(\lambda)$ is extracted according to eq. (2)[1].

$$
n_{\mathrm{g}}(\lambda)=a-b \lambda_{0}-2 c \lambda_{0}\left(\lambda-\lambda_{0}\right), n_{\mathrm{eff}}(\lambda)=a+b\left(\lambda-\lambda_{0}\right)+c\left(\lambda-\lambda_{0}\right)^{2}
$$

where $\mathrm{a}=n_{\text {eff }}\left(\lambda_{0}\right)=3.23, \mathrm{~b}=n_{\text {eff }}\left(\lambda_{0}\right), \mathrm{c}=n_{\text {eff }}{ }^{\prime}\left(\lambda_{0}\right)$. Fourth, perform the FFT to the modified power spectrum $P\left(\lambda \cdot n_{\text {eff }}\left(\lambda_{0}\right) / n_{\text {eff }}(\lambda)\right)$ instead of the raw data $P(\lambda)$ with a rectangular window. Fifth, calculate $n_{\mathrm{g}}\left(\lambda_{0}\right)$ by using the time delay difference from the corrected result. In this way, the dispersion induced limitations to the temporal resolution and the accuracy of the group refractive index will be removed.

\section{MEASUREMENTS}

The OFDR system is experimentally investigated with the DUT fabricated by Smart Photonics through the JePPIX.eu multi-project wafer (MPW) service. The DUT contains shallow- and deep-etched straight waveguides based on indium-phosphide (InP) with width of $2 \mu \mathrm{m}$ and $1.5 \mu \mathrm{m}$, respectively. A wavelength span of $100 \mathrm{~nm}$ with a step of $0.01 \mathrm{~nm}$ of the tunable laser source (Agilent $81600 \mathrm{~B}$ ) is used in our measurements. The interference fringes of the transmitted light are recorded by a power meter (Agilent 81636B). Data processing is done by
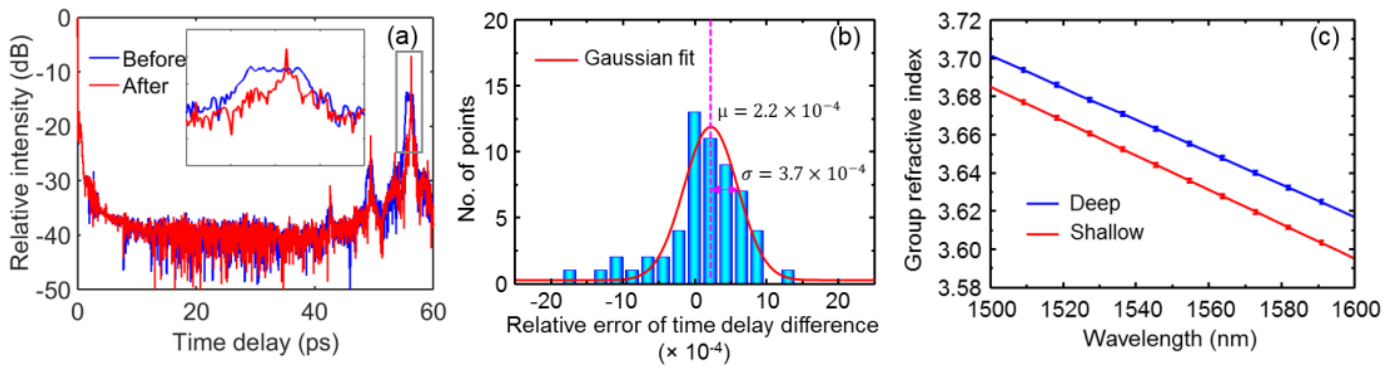

Fig. 2. (a) The reflection distributions in temporal domain before and after de-embedding dispersion. (b) The distribution of relative error of time delay difference. (c) The extracted wavelength dependent group refractive index of shallow- and deep-etched waveguides.

following the numerical algorithm discussed above. We use a moving rectangular window with a width of $20 \mathrm{~nm}$. The distributions of the reflections as a function of the time delay before and after de-embedding dispersion are shown in Fig. 2(a). It shows a much sharper peak of the back facet reflection after de-embedding dispersion. The inset is a zoomed picture of the back facet reflections. Therefore its location $\tau_{\mathrm{b}}$ can be determined with much higher accuracy, limited by the temporal resolution of the OFDR. We use the full width at half maximum (FWHM) of the back reflection peak to determine the temporal resolution $\delta\left(\tau_{\mathrm{b}}-\tau_{\mathrm{f}}\right)$. The distribution of the relative error in time delay difference $\delta\left(\tau_{\mathrm{b}}-\tau_{\mathrm{f}}\right) /\left(\tau_{\mathrm{b}}-\tau_{\mathrm{f}}\right)$ of 50 independent back reflection peaks is calculated and plotted in Fig. 2(b). A fitted Gaussian curve of the distribution is shown as the red line, indicating a relative error of time delay difference of $(5.4 \pm 1.7) \cdot 10^{-4}$. The wavelength dependent group refractive index $n_{\mathrm{g}}(\lambda)$ is extracted, for both shallow- and deep-etched waveguides, shown as Fig. 2(c). The error bar is determined by the deviation of the measured results.

\section{CONCLUSIONS AND ACKNOWLEDGEMENTS}

We presented a high-resolution OFDR method with de-embedded group-velocity dispersion in the device under test. Both improved relative error of the chip length and the imporved temporal resolution of the OFDR method contribute to a relative accuracy as low as $10^{-4}$ for the group refractive index measurement. The wavelength dependence of the group refractive index can also be extracted with a relative accuracy of $10^{-3}$. We acknowledge support by the Dutch Technology Foundation STW for project 13538, NextGen.

\section{REFERENCES}

[1] S. Dwivedi et al., "Experimental extraction of effective refractive index and thermo-optic coefficients of silicon-on-insulator waveguides using interferometers," J. Lightwave Technol., Vol. 33, no. 21, pp. 4471, 2015.

[2] D. Melati et al., "Waveguide-based technique for wafer-level measurement of phase and group effective refractive indices," J. Lightwave Technol., Vol. 34, no. 4, pp. 1293, 2016.

[3] D. Zhao et al., "Optical frequency domain reflectometry for characterization of waveguide crossings," Proceedings of 18the Eur. Conf. on Int. Opt., pp. o-14, 2016.

[4] B. J. Soller et al., "High resolution optical frequency domain reflectometry for characterization of components and assemblies," Opt. Express, Vol. 13, no. 2, pp. 666, 2005.

[5] U. Glombitza et al., "Coherent frequency-domain reflectometry for characterization of single-mode integrated-optical waveguides," J. Lightwave Technol., Vol. 11, no. 8, pp. 1377, 1993. 